Int. J. Dev. Biol. 58: 139-146 (2014)

doi: $10.1387 / \mathrm{ijdb} .130348 \mathrm{mb}$

\title{
Role of uterine stromal-epithelial crosstalk in embryo implantation
}

\author{
ALISON M. HANTAK ${ }^{1}$, INDRANI C. BAGCHI ${ }^{2}$ and MILAN K. BAGCHI*,1 \\ ${ }^{1}$ Departments of Molecular \& Integrative Physiology and ${ }^{2}$ Comparative Biosciences, \\ University of Illinois at Urbana-Champaign, Urbana, IL, USA
}

\begin{abstract}
Embryo implantation is a crucial step for successful pregnancy. Prior to implantation, the luminal epithelium undergoes steroid hormone-induced structural and functional changes that render it competent for embryo attachment. Subsequent invasion of the embryo into the maternal tissue triggers differentiation of the underlying stromal cells to form the decidua, a transient tissue which supports the developing embryo. Many molecular cues of both stromal and epithelial origin have been identified that are critical mediators of this process. An important aspect of uterine biology is the elaborate crosstalk that occurs between these tissue compartments during early pregnancy through expression of paracrine factors regulated by the steroid hormones estrogen and progesterone. Aberrant expression of these factors often leads to implantation failure and infertility. Genetically-engineered mouse models have been instrumental in elucidating what these paracrine factors are, what drives their expression, and what their effects are on neighboring cells. This review provides an overview of several well-characterized signaling pathways that span both epithelial and stromal compartments and their function during implantation in the mouse.
\end{abstract}

KEY WORDS: steroid hormone, uterine receptivity, uterine proliferation, uterine differentiation, pregnancy

\section{Introduction}

For successful pregnancy, the uterus must undergo a series of structural and functional changes early in gestation to promote invasion of the embryo into maternal tissue, a process known as implantation. These changes are driven by the coordinated actions of $17 \beta$-estradiol $(E)$ and progesterone $(P)$ (Ramathal et al., 2010; Cha et al., 2012). In mice, the steroid hormone-regulated events leading to implantation are well defined. During days 1-2 of pregnancy (day 1 corresponds to the detection of a copulatory plug), $\mathrm{E}$ is the predominant hormone driving proliferation of the luminal and glandular epithelium. By day 4 of pregnancy, with the rise of $P$ secreted from the newly formed corpora lutea, the uterine epithelium shifts from a proliferative to a differentiated state, and becomes receptive to embryo attachment. Development of a receptive uterus involves structural and functional remodeling of the uterine epithelium. During this process, the epithelial cells lose polarity through down-regulation of the cell-cell adhesion molecule E-cadherin, exhibit an inhibition of the cell surface glycoprotein mucin 1 (MUC1), and develop protrusions along the apical surface (Thie et al., 1995; Surveyor et al., 1995; Nikas and Psychoyos, 1997). As the uterus attains receptivity, the trophectoderm layer of the embryo attaches to the uterine luminal epithelium and begins to invade into the underlying stroma (Ramathal et al., 2010; Cha et al., 2012).

Attachment of the embryo to the receptive epithelial lining triggers proliferation and differentiation of the surrounding stroma into secretory decidual cells, a process known as decidualization (Ramathal et al., 2010; Cha et al., 2012). In mice, this transition

\footnotetext{
Abbreviations used in this paper: AREG, amphiregulin; BMP2, bone morphogenetic protein 2; COUP-TFII, chicken ovalbumin upstream promoter-transcription factor II; E, 17 3 -estradiol; EGFR, epidermal growth factor; EREG, epiregulin; ER, estrogen receptor; ERK1/2, extracellular signal-regulated kinases 1 and 2; GP130, glycoprotein 130; HAND2, heart and neural crest derivatives-expressed protein 2; HB-EGF, heparin binding epidermal growth factor; FGF, fibroblastic growth factor; FGFR, FGF receptor; GSK3 $\beta$, glycogen synthase kinase $3 \beta$; HOXA10, homeobox A10 ; IGF1, insulin-like growth factor 1; IGF1R, IGF1 receptor; IGFBP5, insulin-like growth factor binding protein 5; IHH, Indian hedgehog; IRS, insulin receptor substrate; JAK, Janus kinase; LTF, lactotransferrin; LIF, leukemia inhibitory factor; LIFR, LIF receptor; MSX, muscle segment homeobox gene family member; MUC1, mucin 1; P, progesterone; PI3K/Akt, phosphatidylinositol 3-kinase/Akt; PTC, patched membrane receptor; PR, progesterone receptor; SMO, smoothened; STAT3, signal transducer and activator of transcription 3; WNT, wingless-type MMTV integration site.
}

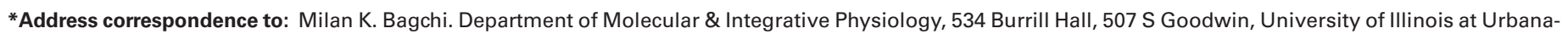
Champaign, Urbana, IL, USA. E-mail: mbagchi@life.illinois.edu 
begins on day 4.5 of pregnancy and is completed by day 8 . This transient tissue supports the invading embryo and mediates the formation of maternal blood vessels to provide oxygen and nutrients to the embryo prior to placentation. By day 10.5 of pregnancy, embryo invasion is complete and the decidua undergoes regression. Perturbation of molecular pathways involved in decidualization, embryo invasion, and blood vessel formation culminates in pregnancy loss and infertility. Because infertility is a problem faced by many couples trying to conceive, it is critical to understand the molecular events occurring during pregnancy to help improve assisted reproductive technology.

\section{Role of $E$ and $P$ receptors during early pregnancy: lessons learned from knockout mice}

During early pregnancy, both $\mathrm{E}$ and $\mathrm{P}$ play pivotal roles in orchestrating the structural and functional changes in the uterus that allow it to support the growth and development of the embryo. $\mathrm{E}$ and $P$ are synthesized from cholesterol in the ovary and can diffuse into a target cell to act on their cognate receptors. The estrogen receptors, ER $\alpha$ and $E R \beta$, and the progesterone receptors, PR-A and $\mathrm{PR}-\mathrm{B}$, are transcription factors that exist in the cytoplasm in the absence of their respective hormones. Hormone binding activates the receptor, promoting receptor dimerization and translocation to the nucleus. Activated ER and PR bind to specific genomic sites to activate or repress the expression of their target genes. Through the use of chromatin immunoprecipitation coupled to high throughput sequencing, genome-wide binding sites of ER and $P R$ have been identified, representing consensus sequences GGTCAnnnTGACC and AGAACAnnnTGTTCT, respectively (Hewitt et al., 2012; Rubel et al., 2012). ER and PR can also regulate gene expression by tethering to other transcription factors. Binding of these receptors can also occur at distal enhancer regions, which then form complexes with the proximal promoter through a chromosomal looping event (Pan et al., 2008; Li et al., 2013).

The generation of mutant mouse models lacking functional ER or PR has provided great insight into the role of steroid hormoneregulated gene expression in the uterus during pregnancy. The PR knockout (PRKO) females are infertile, primarily due to an ovulation defect (Lydon et al., 1995). Their uteri are hyperplastic and non-receptive to the implanting embryo. These mutant mice also fail to mount a decidual response following artificial stimulation of their hormone-primed uteri. Mice lacking PR exclusively in the epithelium are also infertile and show persistent proliferation of the luminal epithelium (Franco et al., 2012). Together, these mouse models establish a clear role of PR signaling in the transition of the uterine epithelium from a proliferative to a receptive state.

$\mathrm{ER} \alpha$ is the predominant $\mathrm{ER}$ isoform that mediates critical uterine functions during the reproductive cycle and pregnancy. Its loss results in female infertility and insensitivity to the mitogenic effects of $E$ (Hewitt and Korach, 2003). Loss of $E R \beta$, on the other hand, has no effect on uterine function but shows reduced fertility due to an ovarian defect (Krege et al., 1998). Generation of an epithelial-specific deletion of $\mathrm{ER} \alpha$ also results in female infertility (Winuthayanon et al., 2010). Surprisingly, loss of epithelial ER $\alpha$ does not prevent E-induced epithelial cell proliferation, suggesting that ER $\alpha$ action in the stroma is critical for mediating this event. These findings are reminiscent of the earlier tissue recombination experiments performed by Cunha et al., who demonstrated the interdependency between the endometrial epithelium and stroma (Cooke et al., 1997; Kurita et al., 1998).

During the past decade, great strides have been made towards increasing our knowledge of uterine biology both with in vitroand in vivo model systems. Because of the invasive nature of implantation research and the ethical restrictions for human studies, the study of implantation in the human is extremely limited. Development of knockout mouse models has been instrumental in delineating the mechanisms involved in this complex process. Furthermore, conditional deletion of genes of interest using the Cre-Lox strategy has allowed us to study their function in an in vivo context. Much of the work establishing uterine stromal-epithelial dialogue has been performed in the mouse, and the purpose of this review is to document the knowledge gained from various knockout mouse models exhibiting implantation defects. It is becoming evident that the luminal and glandular epithelia and underlying stroma act as interconnected functional units within the uterus rather than individual, autonomous compartments. This review will examine the critical signals of either epithelial or stromal origin that regulate implantation.

\section{Epithelial factors regulating stromal function}

\section{LIF and STAT3}

Leukemia inhibitory factor (LIF) is perhaps the most well characterized paracrine factor of epithelial origin that regulates implantation. It is a secreted cytokine belonging to the interleukin (IL-6) family, and maintains the pluripotency of mouse embryonic stem cells by inhibiting their differentiation (Smith et al., 1988). It binds to the cell surface LIF receptor (LIFR), triggering its interaction with the signal transducer glycoprotein 130 (GP130), which activates Janus kinase (JAK), a nonreceptor tyrosine kinase, and mediates the phosphorylation and activation of the transcription factor signal transducer and activator of transcription 3 (STAT3) (Yang et al., 1995). Spatiotemporal analysis of LIF showed its expression predominantly in the glandular epithelium on day 4 of pregnancy (Bhatt et al., 1991; Yang et al., 1995; Song et al., 2000). LIF is also present in the luminal and glandular epithelium on day 1 , but its expression decreases on day 2 before increasing again on day 4, suggesting a biphasic pattern of induction (Yang et al., 1995). LIFR and GP130 follow a similar pattern of biphasic expression in the luminal and glandular epithelium, consistent with the view that LIF produced in the glandular epithelium acts on the luminal epithelium around the time of implantation. LIFR and GP130 are also present in the uterine stroma on day 5 of pregnancy, suggesting potential regulation of stromal function by epithelial LIF. In the uterus, LIF activates the JAK-STAT pathway, culminating in phosphorylation and activation of STAT3 (Cheng et al., 2001). Transactivation of STAT3 in the luminal epithelium is tightly regulated, showing nuclear localization on day 4 and cytoplasmic localization on days 3 and 5 .

Deletion of the Lifgene in the mouse germ line results in female infertility, characterized by a defect in implantation and decidualization that can be rescued by administering recombinant LIF (Stewart et al., 1992; Chen et al., 2000). Further characterization of Lif-null mice showed that uterine expression of $E R$ and $P R$ is unaffected (Chen et al., 2000; Song et al., 2000). However, the expression of several EGF-like growth factors, such as heparin binding epidermal growth factor (Hbegf), amphiregulin (Areg), and epiregulin (Ereg), 
which are normally induced in the luminal epithelium adjacent to the blastocyst on day 4 of pregnancy, are notably absent in Lif-null mice (Song et al., 2000). Although the precise function of these EGF-like growth factors is not fully understood, their expression is required for successful pregnancy (Xie et al., 2007). Since the EGF receptors (EGFR) are expressed on the stromal cells during pregnancy, this may indicate that EGF-like growth factors are paracrine mediators acting on the stroma to drive stromal proliferation and differentiation. This view is supported by the observation that decidualization defects arising from LIF-deficiency could be partially rescued by intrauterine administration of EGF ligand (Pawar et al., 2013).

Analyses of Lif-null mice have been critical in delineating downstream molecular cues involved in implantation and decidualization. In the absence of LIF, the transactivation and nuclear localization of STAT3 is lost. Pharmacological studies showed that STAT3 activation is required for implantation (Catalano et al., 2005). To further characterize its role during pregnancy, Stat3 was deleted from both epithelial and stromal cells of the uterus using PR-Cremediated excision of the floxed Stat3 gene (Lee et al., 2013; Sun et al., 2013). Loss of uterine Stat3 in Stat3 ${ }^{d / d}$ mice is associated with infertility due to defects in implantation and decidualization. Stat $3^{d / d}$ uteri show increased epithelial expression of the E-regulated genes lactotransferrin ( $L t f)$ and Muc1, consistent with heightened E signaling. Stat3 null uteri also exhibit persistent proliferation in the luminal epithelium and a lack of proliferation in the underlying stroma on day 4 of pregnancy, indicating the non-receptive state of the uterus (Sun et al., 2013). STAT3 also regulates implantation through modulation of adhesion molecules in the uterine epithelium. Prior to implantation, the junctional molecules E-cadherin and

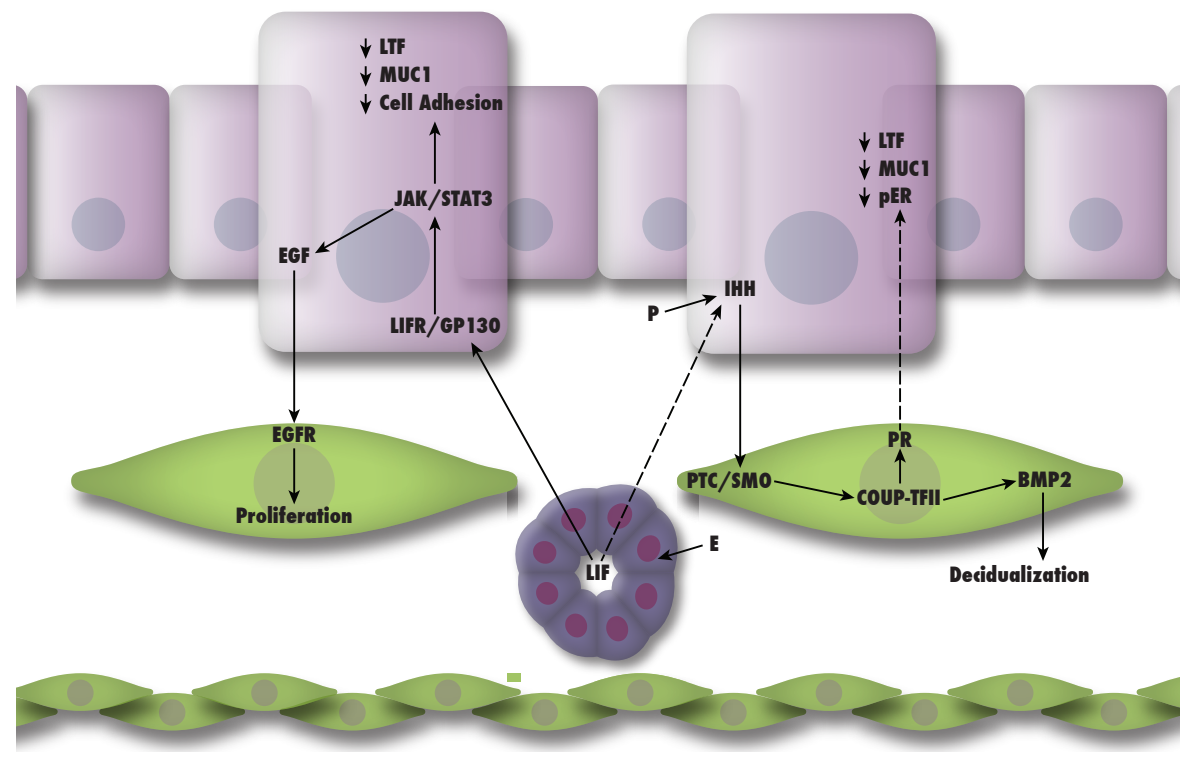

Fig. 1. Uterine luminal (pink) and glandular (purple) epithelial cells mediate changes in the stroma (green) through paracrine interactions. Dashed lines represent indirect activation or inhibition. Abbreviations: estrogen (E); estrogen receptor (ER); phosphorylated ER (pER); progesterone (P); progesterone receptor (PR); leukemia inhibitory factor (LIF); LIF receptor (LIFR); glycoprotein 130 (GP130); Janus kinase (JAK); signal transducer and activator of transcription 3 (STAT3); lactotransferrin (LTF); mucin 1 (MUC1); epidermal growth factor (EGF); EGF receptor (EGFR); Indian hedgehog (IHH); patched/smoothened (PTC/SMO); chicken ovalbumin upstream promoter transcription factor II (COUP-TFII); bone morphogenetic protein 2 (BMP2). claudin-1 maintain cell-cell adhesion and create a para-cellular barrier (Singh and Aplin, 2009). To establish receptivity, these molecules must be down-regulated to allow embryo invasion. Indeed, an epithelial-specific deletion of Stat3 shows that the loss of this factor is associated with increased E-cadherin and claudin-1 expression during the window of receptivity (Pawar et al., 2013). Collectively, these studies show that the loss of LIF-STAT3 signaling culminates in an undifferentiated uterine luminal epithelium that is non-responsive to the embryo.

Progesterone responsiveness is also impaired in Lif-null and Stat3 ${ }^{d / d}$ uteri, as indicated by aberrant expression of PR target genes, including homeoboxA10 (Hoxa10), Indian hedgehog (Ihh), and amphiregulin (Areg) (Daikoku et al., 2004; Wakitani etal., 2008; Lee et al., 2013; Sun et al., 2013; Pawar et al., 2013). Since the of ER and PR does not differ significantly between Stat3 $3^{\text {f/f }}$ and Stat ${ }^{d / d}$ mice, it was suggested that PR signaling is disrupted by the loss of STAT3 expression (Sun et al., 2013). Indeed, it was onstrated that PR interacts directly with STAT3 during the periimplantation phase (Lee et al., 2013). These findings indicate that $P R$ and STAT3 act in concert to regulate a subset of $P$ responsive genes that are critical for decidualization.

Collectively, these data establish that LIF, produced by the glandular epithelium under estrogen stimulation, acts on the luminal epithelium to activate the JAK-STAT signaling pathway and mediates a shift from a proliferative state to a differentiated state through the down-regulation of ER target genes and cell-cell junctional of the EGF signaling pathway and controls stromal differentiation by controlling P-regulated genes, such as $\mathrm{IHH}$, a key signal that functionally connects the epithelium and stroma. Fig. 1 provides a schematic representation of the LIF-STAT3 axis, spanning both the luminal and glandular epithelium and influencing cellular functions in the stroma.

\section{IHH and COUP-TFII}

Indian hedgehog $(\mathrm{IHH})$ is a member of the hedgehog gene family that is involved in the proliferation and development of several different tissue types. The hedgehog family members trigger a signaling cascade through binding of the patched membrane receptor (PTC) and downstream recruitment and activation of the intracellular transducer smoothened (SMO) (McMahon, 2000). These signaling events activate the downstream transcription factors Gli and chicken ovalbumin upstream promoter-transcription factor II (COUP-TFII) to regulate cell proliferation and differentiation. In the uterus, $\mathrm{IHH}$ expression is detected in the luminal and glandular epithelium on day 3 of gestation, reaches peak expression on day 4 , and rapidly decreases by day 5 (Paria et al., 2001; Matsumoto et al., 2002; Takamoto et al., 2002). Expression of PTC, the $\mathrm{IHH}$ receptor, and COUP-TFII is also observed on days 4-5 of pregnancy in the uterine stromal cells, consistent with the concept that they are activated 
downstream of $\mathrm{IHH}$ (Paria et al., 2001, Matsumoto et al., 2002; Takamoto et al., 2002). This expression pattern suggests that $\mathrm{IHH}$, a diffusible factor produced in the epithelium, controls stromal functions by paracrine mechanisms via its receptor in the stromal cells.

Use of the PRKO mouse model identified $\mathrm{IHH}$ as a P-regulated factor (Matsumoto et al., 2002; Takamoto et al., 2002). To elucidate how PR regulates $\mathrm{IHH}$, tissue recombinant experiments were performed using epithelium and stroma isolated from wild type and PRKO mice (Simon et al., 2009). These experiments established that stromal PR is required for epithelial expression of $/ \mathrm{hh}$ and downstream stromal expression of Ptc and Coup-tfII, while epithelial PR is insufficient and expendable. However a later study, using a uterine epithelium PR knockout generated by Wnt7a-Cre, showed a reduction in Ihh expression with loss of epithelial PR, suggesting that epithelial PR may not be completely dispensable for $\mathrm{IHH}$ expression in the pregnancy scenario (Franco et al., 2012). Moreover, the proximal promoter of the Ihh gene contains a progesterone response element that both shows PR occupancy and responsiveness under progesterone stimulation, suggesting that $I h h$ is a direct target of PR within the uterine epithelium. Other groups have also shown that aberrant LIF expression and signaling correlate with reduced Ihh expression (Wakitani et al., 2008; Sun et al., 2013).

To study the function of $\mathrm{IHH}$ within the uterus, a conditional knockout mouse, I $h h^{d / d}$, was generated using a PR-driven Cre to bypass the perinatal lethality of global Ihh-null mice (Lee et al., 2006). Deletion of $/ h h$ in the uterus results in infertility due to implantation defects, preventing blastocyst attachment. $/ \mathrm{h} h^{d / d}$ mice show a higher expression of MUC1 mRNA and protein than floxed control mice, suggesting uteri fail to achieve a receptive state in the absence of Ihh. Microarray analysis identified other ER target genes, including lactotransferrin ( $L t f)$, wingless-type MMTV integration site (WNT) family member 4 (Wnt4), and insulin-like growth factor binding protein 5 (Igfbp5), that are up regulated in Ihh-null uteri, suggesting $\mathrm{IHH}$ may play a role in modulating ER activity during the peri-implantation period (Franco et al., 2010). Additionally, artificial decidualization experiments showed that $I h h^{d / d}$ mice fail to initiate the progesterone-induced stromal cell proliferation and vascularization that occurs just prior to decidualization during the peri-implantation phase (Lee et al., 2006). Indeed, the cell cycle regulatory factor CCND1 and the minichromosome maintenance family member $\mathrm{MCM} 3$, which are expressed in the uterine stroma of control mice undergoing artificial decidualization, are undetectable in Ihh-null uteri (Franco et al., 2010). Restoration of stromal cell proliferation and a partial rescue of angiogenesis can be achieved upon administration of a smoothened agonist, but decidualization itself is still impaired, suggesting that the hedgehog signaling cascade is critical for driving pre-decidualization events (Lee et al., 2006). Deletion of Ihh also down-regulates EGFR in the stromal compartment, identifying it as a downstream target of the $\mathrm{IHH}$ signaling pathway. Microarray analysis further identified other members of the EGF receptor family that are regulated by $\mathrm{IHH}$, including Erbb2/Her2, Erbb3/Her3, and Erbb4/Her4 (Franco et al., 2010). EGF signaling has been shown to be active during implantation, and its dysregulation could contribute to the observed implantation failure (Xie et al., 2007).

Loss of Ihh in the uterine epithelium is associated with aberrant gene expression in the stroma, indicating that $\mathrm{IHH}$ is acting in a paracrine manner. COUP-TFII was identified as the stromal factor mediating these changes. Deletion of Coup-tfll (Coup-tfl/d/d $)$ using PR-Cre leads to infertility resulting from failed embryo attachment (Kurihara et al., 2007). Similar to the $/ h h^{d / d}$ mice, Coup-tf/I/d mice also fail to undergo artificial decidualization, a defect linked to decreased expression of bone morphogenetic protein 2 (BMP2), a factor induced in the uterine stroma in response to progesterone stimulation (Kurihara et al., 2007; Lee et al., 2007; Li et al., 2007). Stromal PR is also dramatically reduced in Coup-tfll null uteri, suggesting that progesterone driven stromal-epithelial interactions may be influenced by the IHH-COUP-TFII pathway (Kurihara et al., 2007). Additionally, Coup-tf/I/d mice show increased epithelial ER $\alpha$ expression and increased estrogen activity during the window of receptivity compared to control mice, resulting in increased LTF and MUC1 expression and failure to undergo the epithelial remodeling necessary for implantation (Kurihara et al., 2007; Lee et al., 2010). Taken together, these experiments establish that the IHH-COUP-TFII axis, as shown in Fig. 1, controls epithelialstromal signaling that mediates both the suppression of ER $\alpha$ activity and subsequent luminal epithelium remodeling necessary for implantation. Furthermore, despite its transient induction, $\mathrm{IHH}$ is also critical for decidualization through the COUP-TFII mediated induction of BMP2.

\section{Stromal factors regulating epithelial function}

\section{Estrogen receptor}

Prior to implantation, the preovulatory surge of E, acting via $\mathrm{ER} \alpha$, promotes epithelial proliferation. Since both stromal and epithelial compartments express $\mathrm{ER} \alpha$, a logical assumption is that E-induced epithelial proliferation is controlled directly through epithelial ER $\alpha$. However, uterine physiology is much more complex. Cunha's group performed a series of tissue recombination experiments using stroma and epithelium from wild type and $E R \alpha$-null mice; by placing the recombinants under the renal capsule of adult mice, they demonstrated that estrogen-driven epithelial cell proliferation is controlled by stromal ER $\alpha$ rather than epithelial ER $\alpha$ (Cooke et al., 1997). They also showed that the expression of LTF, an E-driven secretory protein, is partially retained in recombinants containing $E R \alpha$-null epithelium and wild-type stroma, but completely lost in recombinants containing wild-type epithelium and ER $\alpha$-null stroma (Buchanan et al., 1999). The E-mediated down regulation of PR in the uterine epithelium was also found to be dependent on stromal but not epithelial $\mathrm{ER} \alpha$ (Kurita, et al., 2000).

These earlier observations were supported later by the generation of a uterine epithelial-specific ER $\alpha$ knockout mouse using Wnt7a-Cre (Winuthayanon et al., 2010). These conditional mutant mice, lacking $\mathrm{ER} \alpha$ in the uterine epithelium, retain the ability to exhibit uterine wet weight gain and epithelial proliferation in response to $E$ treatment. These results provide strong evidence that E-induced epithelial proliferation, a major event promoting preimplantation uterine growth, is driven by paracrine factors controlled by stromal ER $\alpha$. One group of candidate stromal $E R \alpha$-induced paracrine factors is the fibroblastic growth factor (FGF) family, namely FGF-1, -2, -9, and -18 (Tsai et al., 2002; Li et al., 2011). FGFs act on cell surface FGF receptors (FGFRs) to mediate downstream activation of extracellular signal-regulated kinases 1 and 2 (ERK1/2) or phosphatidylinositol 3-kinase/Akt (PI3K/Akt) signaling cascades (Eswarakumar et al., 2005). In 
the endometrium, as depicted in Fig. 2, FGFs released from the stroma bind to FGFRs on the uterine epithelium and activate ERK1/2 to promote epithelial proliferation (Li et al., 2011).

\section{IGF1}

Insulin-like growth factor 1 (IGF1) is a peptide hormone that promotes growth (Baker et al., 1996). As expected, global deletion of lgf1 decreases body weight in mice (Baker et al., 1996). Perhaps a less predictable consequence of Igf1 deletion is the resulting infertility in both males and females. Females show an ovulation defect and decreased uterine weight compared to control mice, establishing a role for IGF1 in normal reproductive function. Immunohistochemical analysis during the peri-implantation period demonstrated that on day 4 of pregnancy, IGF1 is detected in both uterine epithelium and stroma. On day 5, its expression is limited to the stroma underlying the implanting embryo (Kapur et al., 1992). Expression of the IGF1 receptor (IGF1R) is detectable in all cell types, but is abundant in the luminal and glandular epithelia (Baker et al., 1996).

Following E stimulation, Igf1 is robustly induced in the uterine stroma and more modestly in the luminal epithelium (Zhu and Pollard, 2007). These observations are validated by the lack of expression observed in ERKO mice stimulated with $\mathrm{E}$ (Hewitt et al., 2010). Moreover, Igf1 appears to be a direct target of ER $\alpha$, containing several estrogen response elements that show ER $\alpha$ occupancy following E stimulation.

The fact that IGF1R is abundantly located on the uterine epithelium suggests that its ligand, IGF1, might be a paracrine mediator of the stromal-epithelial crosstalk involved in epithelial proliferation during the preimplantation phase. One proposed mechanism is through the canonical activation of the cell cycle machinery by activated IGF1R, which forms complexes with the docking protein insulin receptor substrate (IRS) that allows receptor interaction with PI3-kinase (Richards et al., 1998; Zhu and Pollard, 2007). In unstimulated cells, glycogen synthase kinase $3 \beta$ (GSK3 $\beta$ ) prevents nuclear accumulation of cyclin D1, a key factor in the G1 to S tran- sition of the cell cycle. Zhu and Pollard (2007) showed that IGF1R signaling is required for $\mathrm{E}$ - induced luminal epithelial proliferation through the inhibition of GSK3 $\beta$. They proposed a mechanism in which IGF1, produced in the stroma, acts via IGF1R in the epithelium to stimulate activation of PI3K/AKT, which in turn phosphorylates and inactivates GSK3 $\beta$, allowing nuclear accumulation of cyclin D1 and cell cycle progression. Other groups suggested that IGF1 regulates progression through the G2/M rather than $\mathrm{G} 1$ phase of the cell cycle (Adesanya et al., 1999; Walker et al., 2010). Whatever the actual mechanism, these studies point to a role of IGF1 in executing $E$-induced epithelial proliferation by acting in a paracrine manner, as shown in Fig. 2.

\section{Progesterone receptor}

It is well established that progesterone has antiproliferative effects in the uterus and its actions are critical during implantation, as shown by the studies performed with the PRKO mouse (Lydon et al., 1995). Tissue recombinant experiments, using stroma and epithelium from wild type and PRKO mice, have demonstrated that stromal PR is essential for eliciting the antiproliferative effects of PR, while epithelial PR signaling is insufficient (Kurita et al., 1998). These observations indicate that stromal PR, rather than the epithelial PR, is dictating epithelial cell function. In support of this concept, Li et al., (2011) demonstrated that the loss of progesterone-driven stromal factor HAND2 results in sustained epithelial proliferation during pregnancy. However, Franco et al., (2012), using an epithelial-specific knockout of PR, reported that epithelial PR is also required for suppressing the mitogenic effects of estrogen, although the mechanism by which this occurs has not been clarified.

\section{HAND2}

Heart and neural crest derivatives-expressed protein 2(HAND2), a basic helix-loop-helix transcription factor found in distinct tissue types, including the neural crest, limb buds, in the developing and adult heart, myenteric and submucosal sympathetic ganglia, and

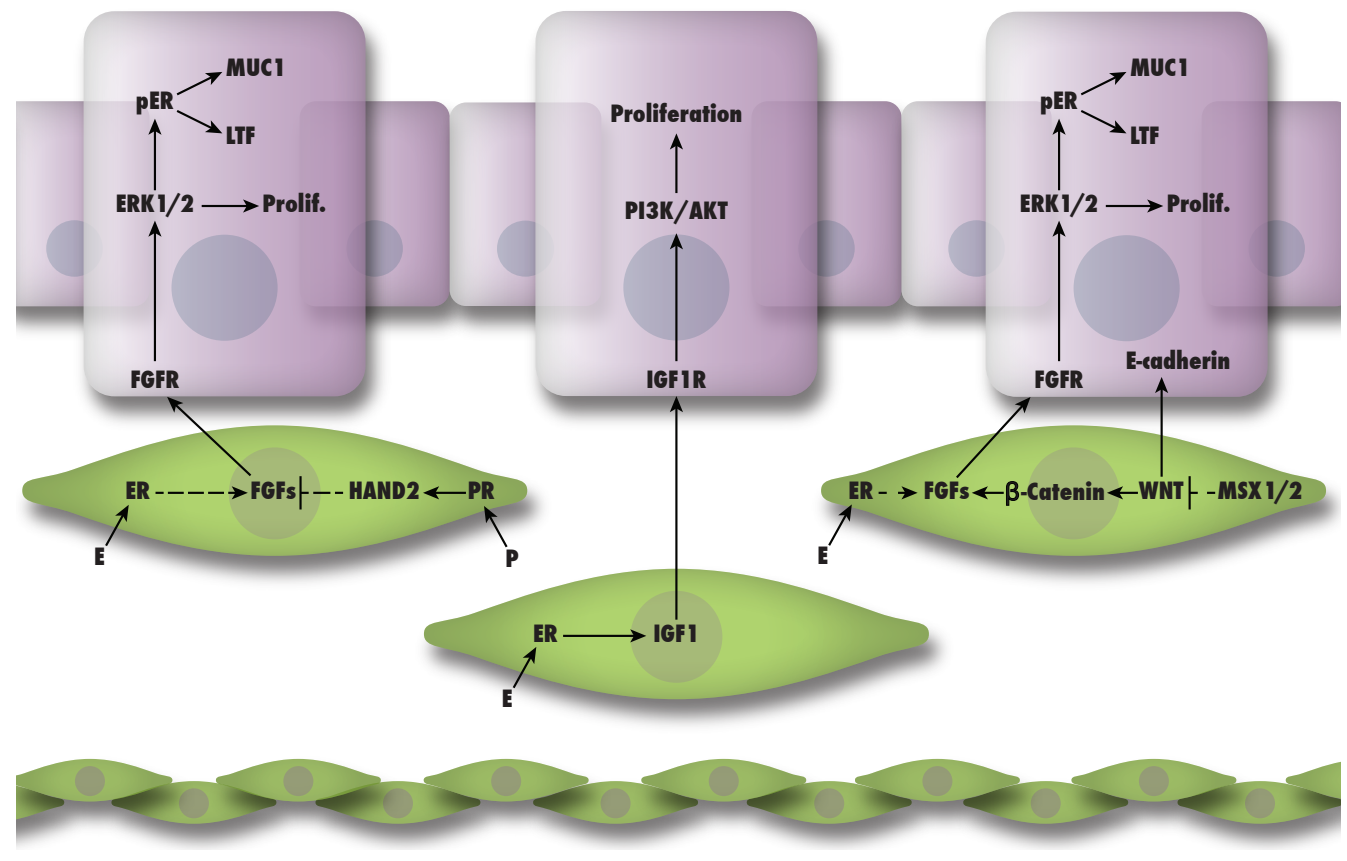

Fig. 2. Uterine stroma (green) regulates epithelial (pink) function through paracrine factors. Dashed lines represent indirect activation or inhibition. Abbreviations: estrogen $(E)$; estrogen receptor (ER); phosphorylated ER (pER); progesterone (P); progesterone receptor $(P R)$; heart-and neural crest derivatives-expressed protein 2 (HAND2); fibroblast growth factors (FGFs); FGF receptor (FGFR); extracellular-signal-regulated kinases 1/2 (ERK1/2); mucin 1 (MUC1); lactotransferrin (LTF); insulin-like growth factor 1 (IGF1); IGF1 receptor (IGF1R); phosphatidylinositol-3-kinase/protein kinase $B$ (PI3K/AKT); muscle segment homeobox genes 1/2 (MSX1/2); wingless-related MMTVintegration site (WNT); proliferation (Prolif.). 
adrenomedullary cells, has emerged as a critical factor in the uterine stroma that regulates epithelial function (Hollenberg et al., 1995; Firulli et al., 2000; Wu and Howard, 2002; Li et al., 2011, Huyen and Bany, 2011). HAND2 expression is induced upon administration of progesterone in ovariectomized mice but not in PRKO mice. Similarly, HAND2 expression can be blocked with administration of the PR antagonist RU486, suggesting that Hand2 is regulated by PR signaling (Li et al., 2011). By day 3 of pregnancy, HAND2 expression is robustly induced in the stroma but is notably absent in the epithelium. Stromal expression persists through implantation and is detectable until day 8.5 of pregnancy, suggesting a role of HAND2 during decidualization (Huyen and Bany, 2011). Deletion of Hand2 from the uterus using PR-Cre $\left(\right.$ Hand $\left.^{d / d}\right)$ results in infertility due to a defect in implantation (Li et al., 2011). Hand $2^{d / d}$ mice show persistent epithelial proliferation in the luminal epithelium on day 4 of pregnancy when none is seen in the floxed controls. Collectively, these results indicate that $\mathrm{Hand}^{\mathrm{d} / \mathrm{d}}$ uteri fail to achieve a receptive state.

HAND2 was shown to inhibit the expression of stromal FGFs, Fgf-1, -2, -9, and -18, which act via FGFR on the luminal epithelial cell surface and induce epithelial proliferation (Li et al., 2011). Using pharmacological FGFR inhibitors, it was shown that attenuation of FGF signaling in Hand2/dd mice leads to cessation of epithelial proliferation. In the uterus, ERK1/2 was determined to be the downstream signal of FGFR responsible for driving epithelial proliferation. Additionally, phosphorylation and activation of epithelial ER $\alpha$ was also shown to be persistent in Hand2 ${ }^{d / d}$ mice, and correlated to increased Ltf and Muc1 expression. Together, these findings present a mechanism, as demonstrated in Fig. 2, by which stromal expression of HAND2 inhibits epithelial proliferation to promote implantation.

\section{MSX1/2}

The muscle segment homeobox gene family members, MSX1 and MSX2, are known regulators of tissue morphogenesis, and play critical roles in uterine stromal-epithelial interactions (Alappat et al., 2003). MSX1 and MSX2 are both expressed in the adult uterus (Daikoku et al., 2011; Nallasamy et al., 2012). During pregnancy, MSX1 and 2 expression is seen in the luminal epithelium on day 1 (Nallasamy et al., 2012). On days 2-3, expression is detected in the glandular epithelium and stroma, and corresponds to an increase in mRNA expression. At the time of implantation on day 4 , both mRNA and protein levels begin to decline and are undetectable by day 5 . Interestingly, the uteri of Lif-null mice show persistent expression of Msx1/2 on day 5 (Daikoku et al., 2004). The tight regulation of these factors in the peri-implantation period suggests that they may play critical roles in implantation.

Conditional deletion of either Msx1 or Msx2results in subfertility, whereas double knockout of both $M s \times 1$ and $M s \times 2\left(M s \times 1^{d / d} M s \times 2^{d / d}\right)$ results in infertility, suggesting a compensatory mechanism between MSX1 and MSX2 (Daikoku et al., 2011; Nallasamy et al., 2012). In double knockouts, the blastocysts fail to attach and invade into the underlying stroma, indicating a defect in implantation. Analysis of the $M s \times 1^{d / d} M s \times 2^{d / d}$ luminal epithelium on day 4 of pregnancy showed elevated ER activity and subsequent increased expression of E-regulated Muc1 and Ltf, as well as persistent epithelial proliferation compared to floxed control animals (Msx $\left.1^{1 / f} M s \times 2^{f / f}\right)$ (Nallasamy et al., 2012). The cell adhesion molecule E-cadherin is also persistently expressed in uteri of $M s \times 1^{d / d} M s \times 2^{d / d}$ mice at day
6, while expression is downregulated in floxed controls, suggesting that MSX1 and MSX2 are also required for the reduced epithelial polarity necessary for embryo implantation (Daikoku et al., 2011).

Microarray analyses of the uterine stroma and epithelium of day 4 pregnant $M s \times 1^{d / d} M s \times 2^{d / d}$ and $M s \times 1^{f / f} M s \times 2^{f / f}$ mice revealed that the WNT family members (Wnt4 and Wnt5) and several FGF family members (Fgf-1, -10, -18, -21) are up-regulated in stroma from $M s \times 1^{d / d} M s \times 2^{d / d}$ mice compared to $M s \times 1^{t / f} M s \times 2^{f / f}$ mice (Nallasamy et al., 2012). WNTs signal through two distinct pathways, the canonical WNT/ $\beta$-catenin-dependent pathway and the noncanonical $\beta$-catenin-independent pathway. Daikoku et al., (2011) proposed that WNT5a signaling through a non-canonical pathway modulates the downstream E-cadherin- $\beta$-catenin complex in the uterine epithelium, resulting in high apical-basal polarity, lack of epithelial breakdown and embryo invasion, and an implantation defect in Msx1/d Msx2 ${ }^{d / d}$ mice. Nallasamy et al., (2012) observed a robust activation of $\beta$-catenin in the stroma of $M s \times 1^{d / d} M s \times 2^{d / d}$ mice on day 4 of pregnancy. Consistent with previous studies linking the canonical WNT signaling to production of FGFs, they reported that increased $\beta$-catenin activation correlates with increased expression of Fgf-10, -18, and -21 in the uterine stroma of $M s \times 1^{d / d} M s \times 2^{d / d}$ mice. These mutant mice also show increased epithelial cell proliferation and expression of MUC1 on day 4 of pregnancy compared to $M s \times 1^{f / f} M s \times 2^{f / f}$ mice. These aberrant activities could be suppressed with an FGFR inhibitor. At first glance, this mechanism appeared very similar to that seen with HAND2. Follow-up studies have shown that HAND2 is normally expressed in $M s \times 1^{d / d} M s \times 2^{d / d}$ mice and vice versa. It is conceivable that that these two pathways converge at a common point downstream, such as the WNT signaling and FGF production.

\section{Conclusion}

In this review, we have discussed signaling molecules that are produced in the epithelial and stromal compartments during the peri-implantation period and act in a paracrine manner to help prepare the maternal tissue for embryo attachment and invasion. Molecular genetic studies in the mouse are uncovering an everincreasing number of molecular cues that control the stromalepithelial dialog, demonstrating the complex relationship between these tissue compartments. Dysregulation of this crosstalk often leads to pregnancy loss and infertility. Continued research to improve our insight into how these two compartments work together will provide the knowledge to explore new techniques to combat infertility and treat other hormone-dependent uterine pathologies.

\section{Acknowledgements}

ICB and MKB are supported by the Eunice Kennedy Shriver NICHD/NIH cooperative agreement grant U54 HD055787 as part of the Specialized Cooperative Centers Program in Reproduction and Infertility Research. AMH is supported by the NIH Predoctoral Traineeship in Endocrine, Developmental \& Reproductive Toxicology T32ES007326. The authors thank Jason Neff for creating the figures.

\section{References}

ADESANYA, O.O., ZHOU, J., SAMATHANAM, C., POWELL-BRAXTON, L. and BONDY, C.A. (1999). Insulin-like growth factor 1 is required for G2 progression in the estradiol-induced mitotic cycle. Proc Natl Acad Sci USA 96: 3287-3291.

ALAPPAT, S., ZHANG, Z.Y. and CHEN, Y.P. (2003). Msx homeobox gene family and 
craniofacial development. Cell Res 13: 429-442.

BAKER, J., HARDY, M.P., ZHOU, J., BONDY, C., LUPU, F., BELLVÉ, A.R. and EFSTRATIADIS, A. (1996). Effects of an Igf1 gene null mutation on mouse reproduction. Mol Endocrinol 10: 903-918.

BHATT, H., BRUNET, L.J. and STEWART, C.L. (1991). Uterine expression of leukemia inhibitory factor coincides with the onset of blastocyst implantation. Proc Natl Acad Sci USA 88: 11408-11412.

BUCHANAN, D.L., SETIAWAN, T., LUBAHN, D.B., TAYLOR, J.A., KURITA, T., CUNHA, G.R. and COOKE, P.S. (1999). Tissue compartment-specific estrogen receptor-alpha participation in the mouse uterine epithelial secretory response. Endocrinology 140: 484-491.

CATALANO, R.D., JOHNSON, M.H., CAMPBELL, E.A., CHARNOCK-JONES, D.S., SMITH, S.K. and SHARKEY, A.M. (2005). Inhibition of Stat3 activation in the endometrium prevents implantation: a nonsteroidal approach to contraception. Proc Natl Acad Sci USA 102: 8585-8590.

CHA, J., SUN, X. and DEY, S.K. (2012). Mechanisms of implantation: strategies for successful pregnancy. Nat Med 18: 1754-1767.

CHEN, J.R., CHENG, J.G., SHATZER, T., SEWELL, L., HERNANDEZ, L. and STEWART, C.L. (2000). Leukemia inhibitory factor can substitute for nidatory estrogen and is essential to inducing a receptive uterus for implantation but is not essential for subsequent embryogenesis. Endocrinology 141: 4365-4372.

CHENG, J.G., CHEN, J.R., HERNANDEZ, L., ALVORD, W.G. and STEWART, C.L. (2001). Dual control of LIF expression and LIF receptor function regulate Stat3 activation at the onset of uterine receptivity and embryo implantation. Proc Natl Acad Sci USA 98: 8680-8685.

COOKE, P.S., BUCHANAN, D.L., YOUNG, P., SETIAWAN, T., BRODY, J., KORACH, K.S., TAYLOR, J., LUBAHN, D.B. and CUNHA, G.R. (1997). Stromal estrogen receptors mediate mitogenic effects of estradiol on uterine epithelium. Proc Natl Acad Sci USA 94: 6535-6540.

DAIKOKU, T., CHA, J., SUN, X., TRANGUCH, S., XIE, H., FUJITA, T., HIROTA, Y., LYDON, J., DEMAYO, F., MAXSON, R. and DEY, S.K. (2011). Conditional deletion of Msx homeobox genes in the uterus inhibits blastocyst implantation by altering uterine receptivity. Dev Cell 21: 1014-1025.

DAIKOKU, T., SONG, H., GUO, Y., RIESEWIJK, A., MOSSELMAN, S., DAS, S.K. and DEY, S.K. (2004). Uterine Msx-1 and Wnt4 signaling becomes aberrant in mice with the loss of leukemia inhibitory factor or Hoxa-10: evidence for a novel cytokine-homeobox-Wnt signaling in implantation. Mol Endocrinol 18: 1238-1250.

ESWARAKUMAR, V.P., LAX, I. and SCHLESSINGER, J. (2005). Cellular signaling by fibroblast growth factor receptors. Cytokine Growth Factor Rev 16: 139-149.

FIRULLI, B.A., HADZIC, D.B., MCDAID, J.R. and FIRULLI, A.B. (2000). The basic helix-loop-helix transcription factors $\mathrm{dHAND}$ and eHAND exhibit dimerization characteristics that suggest complex regulation of function. $J$ Biol Chem 275: 33567-33573.

FRANCO, H.L., LEE, K.Y., BROADDUS, R.R., WHITE, L.D., LANSKE, B., LYDON, J.P., JEONG, J.W. and DEMAYO, F.J. (2010). Ablation of Indian hedgehog in the murine uterus results in decreased cell cycle progression, aberrant epidermal growth factor signaling, and increased estrogen signaling. Biol Reprod82: 783-790.

FRANCO, H.L., RUBEL, C.A., LARGE, M.J., WETENDORF, M., FERNANDEZVALDIVIA, R., JEONG, J.W., SPENCER, T.E., BEHRINGER, R.R., LYDON, J.P. and DEMAYO, F.J. (2012). Epithelial progesterone receptor exhibits pleiotropic roles in uterine development and function. FASEB J 26: 1218-1227.

HEWITT, S.C. and KORACH, K.S. (2003). Oestrogen receptor knockout mice: roles for oestrogen receptors alpha and beta in reproductive tissues. Reproduction 125: 143-149.

HEWITT, S.C., LI, L., GRIMM, S.A., CHEN, Y., LIU, L., LI, Y., BUSHEL, P.R., FARGO, D. and KORACH, K.S. (2012). Research resource: whole-genome estrogen receptor $\alpha$ binding in mouse uterine tissue revealed by ChIP-seq. Mol Endocrinol 26: 887-898.

HEWITT, S.C., LI, Y., LI, L. and KORACH, K.S. (2010). Estrogen-mediated regulation of Igf1 transcription and uterine growth involves direct binding of estrogen receptor alpha to estrogen-responsive elements. J Biol Chem 285: 2676-2685.

HOLLENBERG, S.M., STERNGLANZ, R., CHENG, P.F. and WEINTRAUB, H. (1995). Identification of a new family of tissue-specific basic helix-loop-helix proteins with a two-hybrid system. Mol Cell Biol 15: 3813-3822.

HUYEN, D.V. and BANY, B.M. (2011). Evidence for a conserved function of heart and neural crest derivatives expressed transcript 2 in mouse and human decidualization. Reproduction 142: 353-368.
KAPUR, S., TAMADA, H., DEY, S.K. and ANDREWS, G.K. (1992). Expression of insulin-like growth factor-I (IGF-I) and its receptor in the peri-implantation mouse uterus, and cell-specific regulation of IGF-I gene expression by estradiol and progesterone. Biol Reprod 46: 208-219.

KREGE, J.H., HODGIN, J.B., COUSE, J.F., ENMARK, E., WARNER, M., MAHLER, J.F., SAR, M., KORACH, K.S., GUSTAFSSON, J.A. and SMITHIES, O. (1998). Generation and reproductive phenotypes of mice lacking estrogen receptor beta. Proc Natl Acad Sci USA 95: 15677-15682.

KURIHARA, I., LEE, D.K., PETIT, F.G., JEONG, J., LEE, K., LYDON, J.P., DEMAYO, F.J., TSAI, M.J. and TSAI, S.Y. (2007). COUP-TFII mediates progesterone regulation of uterine implantation by controlling ER activity. PLoS Genet 3: e102.

KURITA, T., LEE, K.J., COOKE, P.S., TAYLOR, J.A., LUBAHN, D.B. and CUNHA, G.R. (2000). Paracrine regulation of epithelial progesterone receptor by estradiol in the mouse female reproductive tract. Biol Reprod 62: 821-830.

KURITA, T., YOUNG, P., BRODY, J.R., LYDON, J.P., O'MALLEY, B.W. and CUNHA, G.R. (1998). Stromal progesterone receptors mediate the inhibitory effects of progesterone on estrogen-induced uterine epithelial cell deoxyribonucleic acid synthesis. Endocrinology 139: 4708-4713.

LEE, D.K., KURIHARA, I., JEONG, J.W., LYDON, J.P., DEMAYO, F.J., TSAI, M.J. and TSAI, S.Y. (2010). Suppression of ERalpha activity by COUP-TFII is essential for successful implantation and decidualization. Mol Endocrinol 24: 930-940.

LEE, J.H., KIM, T.H., OH, S.J., YOO, J.Y., AKIRA, S., KU, B.J., LYDON, J.P. and JEONG, J.W. (2013). Signal transducer and activator of transcription-3 (Stat3) plays a critical role in implantation via progesterone receptor in uterus. FASEB J 27: 2553-2563.

LEE, K., JEONG, J., KWAK, I., YU, C.T., LANSKE, B., SOEGIARTO, D.W., TOFTGARD, R., TSAI, M.J., TSAI, S., LYDON, J.P. and DEMAYO, F.J. (2006). Indian hedgehog is a major mediator of progesterone signaling in the mouse uterus. Nat Genet 38: 1204-1209.

LEE, K.Y., JEONG, J.W., WANG, J., MA, L., MARTIN, J.F., TSAI, S.Y., LYDON, J.P. and DEMAYO, F.J. (2007). Bmp2 is critical for the murine uterine decidual response. Mol Cell Biol 27: 5468-5478.

LI, Q., KANNAN, A., DEMAYO, F.J., LYDON, J.P., COOKE, P.S., YAMAGISHI, H., SRIVASTAVA, D., BAGCHI, M.K. and BAGCHI, I.C. (2011). The antiproliferative action of progesterone in uterine epithelium is mediated by Hand2. Science 331: 912-916.

LI, Q., KANNAN, A., WANG, W., DEMAYO, F.J., TAYLOR, R.N., BAGCHI, M.K., and BAGCHI, I.C. (2007). Bone morphogenetic protein 2 functions via a conserved signaling pathway involving Wnt4 to regulate uterine decidualization in the mouse and the human. J Biol Chem 282: 31725-31732.

LI, W., NOTANI, D., MA, Q., TANASA, B., NUNEZ, E., CHEN, A.Y., MERKURJEV, D., ZHANG, J., OHGI, K., SONG, X., OH, S., KIM, H.S., GLASS, C.K. and ROSENFELD, M.G. (2013). Functional roles of enhancer RNAs for oestrogen-dependent transcriptional activation. Nature 498: 516-520.

LYDON, J.P., DEMAYO, F.J., FUNK, C.R., MANI, S.K., HUGHES, A.R., MONTGOMERY, C.A. JR, SHYAMALA, G., CONNEELY, O.M. and O'MALLEY, B.W. (1995). Mice lacking progesterone receptor exhibit pleiotropic reproductive abnormalities. Genes Dev 9: 2266-2278.

MATSUMOTO, H., ZHAO, X., DAS, S.K., HOGAN, B.L. and DEY, S.K. (2002). Indian hedgehog as a progesterone-responsive factor mediating epithelial-mesenchymal interactions in the mouse uterus. Dev Biol 245: 280-290.

MCMAHON, A.P. (2000). More surprises in the Hedgehog signaling pathway. Cell 100: $185-188$.

NALLASAMY, S., LI, Q., BAGCHI, M.K. and BAGCHI, I.C. (2012). Msx homeobox genes critically regulate embryo implantation by controlling paracrine signaling between uterine stroma and epithelium. PLoS Genet 8: e1002500.

NIKAS, G. and PSYCHOYOS, A. (1997). Uterine pinopodes in peri-implantation human endometrium. Clinical relevance. Ann N Y Acad Sci 816: 129-142.

PAN, Y.F., WANSA, K.D., LIU, M.H., ZHAO, B., HONG, S.Z., TAN, P.Y., LIM, K.S., BOURQUE, G., LIU, E.T. and CHEUNG, E. (2008). Regulation of estrogen receptor-mediated long range transcription via evolutionarily conserved distal response elements. J Biol Chem 283: 32977-32988.

PARIA, B.C., MA, W., TAN, J., RAJA, S., DAS, S.K., DEY, S.K., and HOGAN, B.L. (2001). Cellular and molecular responses of the uterus to embryo implantation can be elicited by locally applied growth factors. Proc NatIAcad SciUSA98: 1047-1052.

PAWAR, S., STAROSVETSKY, E., ORVIS, G.D., BEHRINGER, R.R., BAGCHI, I.C. 
and BAGCHI, M.K. (2013). STAT3 regulates uterine epithelial remodeling and epithelial-stromal crosstalk during implantation. Mol Endocrinol 27: 1996-2012.

RAMATHAL, C.Y., BAGCHI, I.C., TAYLOR, R.N. and BAGCHI, M.K. (2010). Endometrial decidualization: of mice and men. Semin Reprod Med 28: 17-26.

RICHARDS, R.G., WALKER, M.P., SEBASTIAN, J. and DIAUGUSTINE, R.P. (1998). Insulin-like growth factor-1 (IGF-1) receptor-insulin receptor substrate complexes in the uterus. Altered signaling response to estradiol in the IGF-1 ${ }^{(\mathrm{m} / \mathrm{m})}$ mouse. $J$ Biol Chem 273: 11962-11969

RUBEL, C.A., LANZ, R.B., KOMMAGANI, R., FRANCO, H.L., LYDON, J.P. and DEMAYO, F.J. (2012). Research resource: Genome-wide profiling of progesterone receptor binding in the mouse uterus. Mol Endocrinol 26: 1428-1442.

SIMON, L., SPIEWAK, K.A., EKMAN, G.C., KIM, J., LYDON, J.P., BAGCHI, M.K., BAGCHI, I.C., DEMAYO, F.J. and COOKE, P.S. (2009). Stromal progesterone receptors mediate induction of Indian Hedgehog $(\mathrm{IHH})$ in uterine epithelium and its downstream targets in uterine stroma. Endocrinology 150: 3871-3876.

SINGH, H. and APLIN, J.D. (2009). Adhesion molecules in endometrial epithelium: tissue integrity and embryo implantation. J Anat 215: 3-13.

SMITH, A.G., HEATH, J.K., DONALDSON, D.D., WONG, G.G., MOREAU, J., STAHL, M. and ROGERS, D. (1988). Inhibition of pluripotential embryonic stem cell differentiation by purified polypeptides. Nature 336: 688-690.

SONG, H., LIM, H., DAS, S.K., PARIA, B.C. and DEY, S.K. (2000). Dysregulation of EGF family of growth factors and COX-2 in the uterus during the preattachment and attachment reactions of the blastocyst with the luminal epithelium correlates with implantation failure in LIF-deficient mice. Mol Endocrinol 14: 1147-1161.

STEWART, C.L., KASPAR, P., BRUNET, L.J., BHATT, H., GADI, I., KÖNTGEN, F. and ABBONDANZO, S.J. (1992). Blastocyst implantation depends on maternal expression of leukaemia inhibitory factor. Nature 359: 76-79.

SUN, X., BARTOS, A., WHITSETT, J.A. and DEY, S.K. (2013). Uterine deletion of Gp130 or Stat3 shows implantation failure with increased estrogenic responses. Mol Endocrinol 27: 1492-1501.

SURVEYOR, G.A., GENDLER, S.J., PEMBERTON, L., DAS, S.K., CHAKRABORTY, I., JULIAN, J., PIMENTAL, R.A., WEGNER, C.C., DEY, S.K. and CARSON, D.D. (1995). Expression and steroid hormonal control of Muc-1 in the mouse uterus. Endocrinol. 136: 3639-3647.
TAKAMOTO, N., ZHAO, B., TSAI, S.Y. and DEMAYO, F.J. (2002). Identification of Indian hedgehog as a progesterone-responsive gene in the murine uterus. $\mathrm{Mol}$ Endocrinol 16: 2338-2348.

THIE, M., HARRACH-RUPRECHT, B., SAUER, H., FUCHS, P., ALBERS, A. and DENKER, H.W. (1995). Cell adhesion to the apical pole of epithelium: a function of cell polarity. Eur J Cell Biol 66: 180-191.

TSAI, S.J., WU, M.H., CHEN, H.M., CHUANG, P.C. and WING, L.Y. (2002). Fibroblast growth factor-9 is an endometrial stromal growth factor. Endocrinology 143: 2715-2721.

WAKITANI, S., HONDO, E., PHICHITRASLIP, T., STEWART, C.L. and KISO, Y. (2008) Upregulation of Indian hedgehog gene in the uterine epithelium by leukemia inhibitory factor during mouse implantation. J Reprod Dev 54: 113-116.

WALKER, M.P., DIAUGUSTINE, R.P., ZERINGUE, E., BUNGER, M.K., SCHMITT, M. ARCHER, T.K. and RICHARDS, R.G. (2010). An IGF1/insulin receptor substrate-1 pathway stimulates a mitotic kinase (cdk1) in the uterine epithelium during the proliferative response to estradiol. J Endocrinol 207: 225-235.

WINUTHAYANON, W., HEWITT, S.C., ORVIS, G.D., BEHRINGER, R.R. and KORACH, K.S. (2010). Uterine epithelial estrogen receptor $\alpha$ is dispensable for proliferation but essential for complete biological and biochemical responses. Proc Natl Acad Sci USA 107: 19272-19277.

WU, X. and HOWARD, M.J. (2002). Transcripts encoding HAND genes are differentially expressed and regulated by BMP4 and GDNF in developing avian gut. Gene Expr 10: 279-293.

XIE, H., WANG, H., TRANGUCH, S., IWAMOTO, R., MEKADA, E., DEMAYO, F.J., LYDON, J.P., DAS, S.K. and DEY, S.K. (2007). Maternal heparin-binding-EGF deficiency limits pregnancy success in mice. Proc Natl Acad Sci USA 104: 18315-18320.

YANG, Z.M., LE, S.P., CHEN, D.B., COTA, J., SIERO, V., YASUKAWA, K. and HARPER, M.J. (1995). Leukemia inhibitory factor, LIF receptor, and gp130 in the mouse uterus during early pregnancy. Mol Reprod Dev 42: 407-414.

ZHU, L. and POLLARD, J.W. (2007). Estradiol-17beta regulates mouse uterine epithelial cell proliferation through insulin-like growth factor 1 signaling. Proc Natl Acad Sci USA 104: 15847-15851. 


\section{Further Related Reading, published previously in the Int. J. Dev. Biol.}

Implantation: molecular basis of embryo-uterine dialogue

B C Paria, $\mathrm{H}$ Song and S K Dey

Int. J. Dev. Biol. (2001) 45: 597-605

http://dx.doi.org/10.1387/ijdb.11417904

Endometrial responses to embryonic signals in the primate

Prajna Banerjee and Asgerally T. Fazleabas

Int. J. Dev. Biol. (2010) 54: 295-302

http://dx.doi.org/10.1387/ijdb.082829pb

Local regulation of implantation at the human fetal-maternal interface

Evdokia Dimitriadis, Guiying Nie, Natalie J. Hannan, Premila Paiva and Lois A. Salamonsen Int. J. Dev. Biol. (2010) 54: 313-322

http://dx.doi.org/10.1387/ijdb.082772ed

Critical growth factors and signalling pathways controlling human trophoblast invasion Martin Knöfler

Int. J. Dev. Biol. (2010) 54: 269-280

On the role of placental major histocompatibility complex and decidual leukocytes in implantation and pregnancy success using non-human primate models

Thaddeus G. Golos, Gennadiy I. Bondarenko, Svetlana V. Dambaeva, Edith E. Breburda, and Maureen Durning

Int. J. Dev. Biol. (2010) 54: 431-443

5 yr ISI Impact Factor $(2011)=2.959$
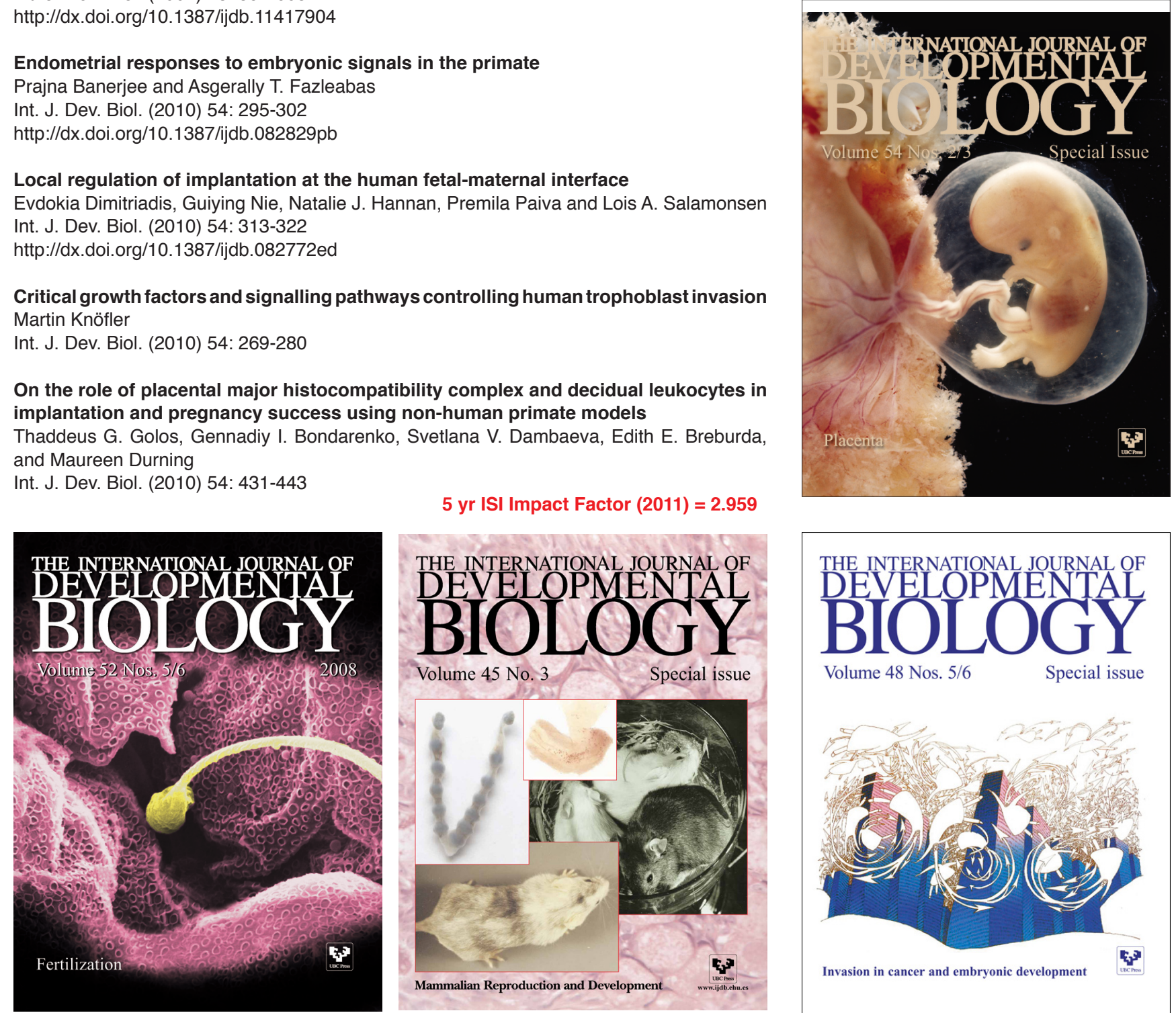

Volume 48 Nos. 5/6

Special issue

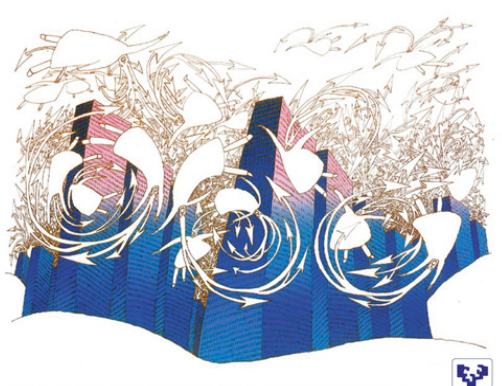

Invasion in cancer and embryonic development

incis 